\title{
SISTEMA AQUÍFERO GUARANI (SAG) E A IMPLEMENTAÇÃO INTEGRAL DO ACORDO SOBRE AS ÁGUAS
}

\author{
GUARANI AQUIFER SYSTEM (SAG) AND THE FULL \\ IMPLEMENTATION OF THE WATER AGREEMENT
}

\section{CESAR LUIZ PASOLD}

Doutor em Direito do Estado pela USP. Mestre em Saúde Pública pela USP. Mestre em Instituições Jurídicas e Políticas pela UFSC. Professor de "Teoria do Estado e da Constituição" no Curso de Doutorado em Ciência Jurídica da UNIVALI, no qual atua nas Linhas de Pesquisa: "Meio Ambiente e Sustentabilidade" e "Principiologia Constitucional e Produção do Direito".

\section{MARIA CLÁUDIA DA SILVA ANTUNES DE SOUZA}

Doutora e Mestre em Derecho Ambiental y de la Sostenibilidad pela Universidade de Alicante - Espanha. Mestre em Ciência Jurídica pela Universidade do Vale do Itajaí - UNIVALI. Professora Permanente no Programa de Pós-Graduação Stricto Sensu em Ciência Jurídica, nos cursos de Doutorado e Mestrado e, na Graduação no Curso de Direito, ambos da Universidade do Vale do Itajaí - UNIVALI. Coordenadora do Grupo de Pesquisa "Direito Ambiental, Transnacionalidade e Sustentabilidade" cadastrado no CNPq/EDATS/UNIVALI. Coordenadora do Projeto de pesquisa aprovado no CNPq intitulado: "Análise comparada dos limites e das possibilidades da avaliação ambiental estratégica e sua efetivação com vistas a contribuir para uma melhor gestão ambiental da atividade portuária no Brasil e na Espanha". Advogada.
E-mail:
mclaudia@univali.br.
Currículo
lattes.

http://lattes.cnpq.br/2095171218854616. Orcid: https://orcid.org/0000-0002-81181071. 


\section{MANOELLE BRASIL SOLDATI}

Doutoranda em Ciência Jurídica pela UNIVALI, em convênio de dupla titulação/cotutela com o Instituto Universitário de Águas e Ciências Ambientais da Universidade de Alicante; Mestre em Ciências Jurídico-Empresariais pela Faculdade de Direito da Universidade de Lisboa-PT; Magistrada do Estado de Santa Catarina.

\section{RESUMO}

Objetivo: O estudo objetiva analisar o tratamento jurídico sobre a exploração e a gestão das águas subterrâneas transfronteiriças; observa-se o tratado firmado para gestão conjunta das águas do Aquífero Guarani - Projeto de Proteção Ambiental e Desenvolvimento Sustentável do Sistema Aquífero Guarani (SAG), com objetivo de conscientização e iminente implantação.

Metodologia: A metodologia empregada: na fase de investigação, o método dedutivo; na fase de tratamento dos dados, o método analítico; e na fase de relato de seus resultados, a base lógica dedutiva.

Resultados: Com alicerce na teoria dos direitos da personalidade, o artigo aborda a pesquisa científica, na medida em que atesta a existência de um patrimônio moral, o que pode ser definido como os direitos extrapatrimoniais porque não encontram, puramente, estimativa em pecúnia - senão quando lesionados e para efeito compensatório ou por motivo de cessão das potencialidades econômicas, que com o direito em si não se confunde —, razão pela qual revelam influxo pecuniário.

Contribuições: A contribuição central do presente trabalho cinge-se em perquirir sobre o Aquífero Guarani; visa-se estimular reflexões sobre a preservação das Águas Subterrâneas e incentivar a gestão compartilhada entre os Estados pelos quais se estende o Aquífero, na busca de um aproveitamento humano da água subterrânea potável de forma sustentável.

Palavras-chave: Acesso à água potável aquíferos transfronteiriços; Aquífero Guarani; gestão compartilhada; desenvolvimento sustentável.

\section{ABSTRACT}

Objective: To analyze the legal treatment of the exploitation and management of cross-border groundwater; the treaty signed for the joint management of the waters of the Guarani Aquifer - Environmental Protection and Sustainable Development 
Project of the Guarani Aquifer System (SAG) is observed, with the objective of raising awareness and imminent implementation.

Methodology: The methodology used: in the investigation phase, the deductive method; in the data processing phase, the analytical method; and in the phase of reporting its results, the deductive logic basis.

Results: Based on the theory of rights of personality, the paper addresses scientific research, insofar as it attests the existence of a moral heritage, which can be defined as extra-patrimonial rights because they do not meet, purely, an estimate in pecuniary - if not when injured and for compensatory effect or due to the assignment of economic potential, which is not confused with the law itself - which is why they reveal a cash inflow.

Contributions: The central contribution of this study is limited to investigating the Guarani Aquifer; the aim is to stimulate reflections on the preservation of groundwater and to encourage shared management between the States through which the aquifer extends, in the search for a sustainable use of human drinking water.

Keywords: Access to drinking water in cross-border aquifers; Guarani Aquifer; shared management; sustainable development.

\section{INTRODUÇÃO}

O presente artigo científico tem como referente apresentar uma contribuição aos estudos das Águas Subterrâneas, notadamente sobre os aquíferos transfronteiriços, ressaltando o relevante tema sob a perspectiva da urgente necessidade de implementar Políticas Públicas e Acordos Internacionais firmados para sua gestão compartilhada.

O seu objeto é o Aquífero Guarani, e o seu objetivo é estimular reflexões sobre a preservação das Águas Subterrâneas e incentivar a gestão compartilhada entre os Estados pelos quais se estende o Aquífero, na busca de um aproveitamento humano da água subterrânea potável de forma sustentável.

A metodologia empregada foi: na fase de investigação, o método dedutivo; na fase de tratamento dos dados, o método analítico; e na fase de relato de seus resultados - consagrado no presente Artigo - foi também empregada a base lógica 
dedutiva.

Dedicar-se ao assunto meio ambiente, nos dias de hoje, é reconhecer, sem dúvida alguma, que se trata de tema reconduzido para o âmbito dos Direitos Fundamentais e, portanto, incluído numa concepção jurídico-política de Solidariedade e Dignidade Humana,

O acesso do ser humano à água potável - imprescindível à sobrevivência de qualquer ser vivo - apresenta-se cada vez mais restrito, seja pela perceptível escassez do bem, seja pelo alto custo cobrado por seu consumo ou pela má gestão e distribuição dos recursos, por isso, a luta pela preservação do meio ambiente relaciona-se diretamente com a proteção dos direitos humanos.

É importante registrar que Luigi Ferrajoli (2011, p. 73/74), ao estabelecer seu conceito e respectiva proposta de dimensão para a categoria “ bens sociais", pontua:

Denominei " bens sociais" aqueles bens - como a água potável, os medicamentos essenciais e os produtos necessários para a alimentação básica- que são objeto dos direitos sociais, isto é , daqueles direitos fundamentais que consistem em prestações, como a alimentação básica e a assistência sanitária."

Dados oficiais da Agência Nacional de Águas indicam que:

$97,5 \%$ da água existente no mundo é salgada e não é adequada ao nosso consumo direto nem à irrigação da plantação. Dos 2,5\% de água doce, a maior parte (69\%) é de difícil acesso, pois está concentrada nas geleiras, $30 \%$ são águas subterrâneas (armazenadas em Aquíferos) e 1\% encontrase nos rios. Logo, o uso desse bem precisa ser pensado para que não prejudique nenhum dos diferentes usos que ela tem para a vida humana.

A compreensão ambiental, cada vez mais, ganha significativo destaque na preocupação ecológica, na busca de uma verdadeira qualidade de vida conferida a seu povo, calcada no alcance e preservação de uma vida digna às presentes e futuras gerações.

As mudanças políticas, econômicas e sociais dos últimos tempos instigaram transformações na ordem ambiental e a forma como passou a incorporar o tema das águas, notadamente dos aquíferos. Nesta linha, a re-descoberta das águas 
subterrâneas, em especial, das transfronteiriças, representa importante ferramenta na busca da proteção e sustentabilidade ambiental.

No Mercosul, a problemática foi objeto de discussão e acordo entre seus Estados integrantes, ressalvando a importância da preservação e gestão compartilhada de águas internacionais. O Projeto para Proteção Ambiental e Desenvolvimento Sustentável do Sistema Aquífero Guarani (SAG), firmado em 2010 pelos Estados integrantes, busca alcançar uma gestão e uso sustentável do Sistema Aquífero Guarani, e representa, mesmo que a passos lentos, um marco institucional, legal e técnico, para um desenvolvimento sustável às presentes e futuras gerações.

\section{A ERA DA CRISE HÍDRICA}

A Sociedade global, imersa em crises mundiais, notadamente, a inevitável crise hídrica, ainda ignora as limitações da natureza e degenera suas reservas.

A falta de acesso à agua potável, uma das substâncias mais fundamentais à vida, coloca populações inteiras em situação de miserabilidade e mortalidade. A poluição desenfreada e despreocupada das águas pela ação do homem, somada à sua finitude, destacam, no cenário mundial, a água potável como verdadeira protagonista do calendário de ações governamentais.

A iniciativa de proteção à água remonta à 1966, quando a Organização das Nações Unidas já mencionava a água como um bem jurídico a ser protegido no Pacto dos Direitos Econômicos, Sociais e Cultuais - ratificado pelo Brasil em 1992 -, ainda que de forma genérica.

Em 1977, com uma agenda ambiental mais acurada, os Estados reuniramse em Mar del Plata, na Argentina, para a Conferência das Nações Unidas sobre Água, sendo este considerado o primeiro encontro internacional para tratar especificamente do tema água, buscando mais cooperação e mecanismos para racionalizar a gestão da água e evitar uma crise mundial de abastecimento. 
A década de 1980 - chamada "Década da Água Potável"- também foi marcada por relevantes avanços históricos na proteção da água e conscientização social, tendo a Organização das Nações Unidas proposto algumas medidas de ação mais urgentes, em razão dos alarmantes números que se apresentavam com mortes e doenças pela falta de água potável. Na sequência, no ano de 1992, na Irlanda, a Conferência Internacional sobre as Águas e o Meio Ambiente também buscava chamar atenção da sociedade mundial para a escassez e finitude da água, incentivando os Estados a adotarem gestões de preservação dos recursos hídricos.

No mesmo ano, no Brasil, realizava-se a conhecida ECO-92 - Conferência das Nações Unidas sobre Meio Ambiente e Desenvolvimento, no Rio de Janeiro -, que, vinte anos depois dos primeiros passos na defesa do meio ambiente e proteção da água, proclamava, por intermédio da chamada Agenda 21, que o objetivo geral era assegurar a oferta de água de boa qualidade para todos os habitantes, mantendo as funções hidrológicas, biológicas e químicas dos ecossistemas, adaptando as atividades do homem aos limites da natureza e lutando para combater as moléstias ligadas a água, dispondo expressamente:

18.2. A água é necessária em todos os aspectos da vida, $O$ objetivo geral é assegurar que se mantenha uma oferta adequada de água de boa qualidade para toda a população do planeta, ao mesmo tempo em que se preserve as funções hidrológicas, biológicas e químicas dos ecossistemas, adaptando as atividades humanas aos limites da capacidade da natureza e combatendo vetores de moléstias relacionadas com a água. Tecnologias inovadoras, inclusive o aperfeiçoamento de tecnologias nativas, são necessárias para aproveitar plenamente os recursos hídricos limitados e protege-los da poluição (Agenda 21, capítulo 18).

Em 22 de março de 1992, também no Rio de Janeiro, foi aprovada a “Declaração Universal dos Direitos da Água - 1992". Esta relevante manifestação foi estabelecida em dez artigos. Dois deles merecem destaque especial ${ }^{1}$ e transcrição literal completa.

O primeiro destaque é para o artigo 5ํㅡ, nestes termos:

\footnotetext{
${ }^{1}$ Aqui estamos reafirmando especialmente estes dois destaques, como já o fizera PASOLD, Cesar Luiz. Ainda sobre a Água Potável. Imbituba: O Popular, 07/04/2006. p.2.
} 
A água não é somente herança de nossos predecessores; ela é, sobretudo, um empréstimo aos nossos sucessores. Sua proteção constitui uma necessidade vital, assim como a obrigação moral do homem para com as gerações presentes e futuras.

E o segundo destaque, no qual há menção expressa à solidariedade princípio universal que extrapola, em dimensão e comprometimento, a fraternidade conectada com o consenso sobre a desigualdade - assim formulado: "O planejamento da gestão da água deve levar em conta a solidariedade e o consenso em razão de sua distribuição desigual sobre a Terra".

A propósito da solidariedade como princípio e sob a perspectiva do Direito Ambiental, lecionam Sarlet e Finsterseifer (2017, p.65):

\begin{abstract}
A Solidariedade expressa a necessidade (e, na forma jurídica, o dever) fundamental de coexistência (e cooperação) do ser humano em um corpo social, formatando a teia de relações intersubjetivas e sociais que se traçam no espaço da comunidade estatal".
\end{abstract}

Mais recentemente, no ano de 2010, a Assembleia Nacional da Organização das Nações Unidas reafirmou o compromisso mundial de preservação e proteção da água, consagrando expressamente o acesso à água potável como um direito humano. O texto da Resolução A/RES/64/292 (ONU, 2017), aprovada na Assembleia Geral da Organização das Nações Unidas declara que o acesso a água limpa e segura e o saneamento é um direito humano essencial para gozar plenamente a vida e todos os outros direitos humanos.

Essas e outras tantas iniciativas, no entanto, parecem não ter sido suficientes para a conscientização mundial, pois os números são cada vez mais inquietantes e a previsão de escassez aproxima-se rapidamente da realidade mundial.

Em 2006, quase dois milhões de crianças morriam todos os anos por falta de um copo de água limpa para beber (PNDU, 2006). Segundo o Relatório da Organização das Nações Unidas sobre o Desenvolvimento de Água 2015 - Água 
para um mundo sustentável, lançado em 20 de março em Nova Deli (Índia), em celebração ao Dia Mundial da Água, "até 2030, o planeta enfrentará um déficit de água de $40 \%$, a menos que seja melhorada dramaticamente a gestão desse recurso precioso"(UNESCO, 2018).

Neste contexto, os holofotes redirecionaram-se aos estudos e exploração das águas subterrâneas, já que constituem a principal reserva hídrica disponível à humanidade. São recursos considerados mais protegidos e menos suscetíveis às alterações climáticas e, de certa forma, da própria poluição humana.

A segunda metade do século XX consagra um modelo de sociedade industrial consolidada e tecnologicamente avançada, notadamente na área da hidrogeologia e perfuração de poços.

\begin{abstract}
Somado a isso, a acumulação de capital gerou novas formas de produção, o que se reverteu na considerável ampliação da utilização dos Aquíferos. Além dos usos tradicionais das águas subterrâneas - abastecimento de água potável para pessoas e animais, produção industrial, irrigação e usos balneários - elas passaram a ser utilizadas pelo processo energético: no resfriamento de centrais termoelétricas e na geração de calor (energia termal); e tornaram-se matéria-prima para extração de componentes como iodo e bromo. Por sua vez, a formação geológica se tornou receptáculo para o armazenamento de determinadas substâncias, como os gases de efeito estufa (CO2), palavras de VILLAR, (2012).
\end{abstract}

O tema das águas subterrâneas, segundo Villar, por muito tempo era objeto de estudos e debates exclusivos das áreas técnicas tradicionais, tais como a geologia e a engenharia (VILLAR, 2007).

Apesar do Planeta Terra - chamado de Planeta Azul - ter sua superfície recoberta por $70 \%$ de água, apenas $2,5 \%$ são de agua doce. Ainda, como bem lembrado por Shiklomanov e Rodda, deste total, $68,7 \%$ estão indisponíveis ao consumo, pois localizam-se nas calotas polares. Os rios e lagos correspondem apenas a $0,3 \%$ do volume disponível, enquanto as águas subterrâneas respondem por $30,1 \%$ do volume de água doce mundial (2003). 


\section{AQUÍFEROS: LIMITES E POSSIBILIDADES DO MARCO LEGAL}

A água dos aquíferos, de um modo geral, é de boa qualidade, já que as camadas de solo e rocha por onde escorrem as águas das chuvas, funcionam como um verdadeiro filtro de impurezas.

Destaca Granziera (2006, p. 35), que se

[...] trata de um extrato subterrâneo de terra, cascalho ou rocha porosa que contem água", conhecido também como "rocha cuja permeabilidade permite a retenção de água, dando origem a águas interiores ou freáticas". Ainda, "formação porosa (camada ou extrato) de rocha permeável, areia ou cascalho, capaz de armazenar e fornecer quantidade significativas de água.

Segundo a Agencia Nacional de Águas (2019), há basicamente três formas de aquíferos, no que concerne à sua porosidade: fraturado, poroso e cárstico, e os definem como "uma reserva de água embaixo do solo, abastecida pela chuva, e funciona como uma espécie de caixa d’água que alimenta os rios".

No entanto, o abastecimento dessas caixas d’água - que ocorre nas chamadas zona de recarga - dá-se de forma lenta já que depende da infiltração das águas da chuva nos locais de fissura das rochas.

Lembra Guimarães (2007, p.33), "que o custo de produção de água subterrânea para consumo humano é 50 vezes mais baixo que o custo de se retirar água de um rio".

É bom lembrar que a captação e uso de águas subterrâneas não é novidade para a humanidade, que desde os povos da Antiguidade já desenvolviam técnicas para tanto ${ }^{2}$, todavia, em que pese já considerada fundamental para sobrevivência,

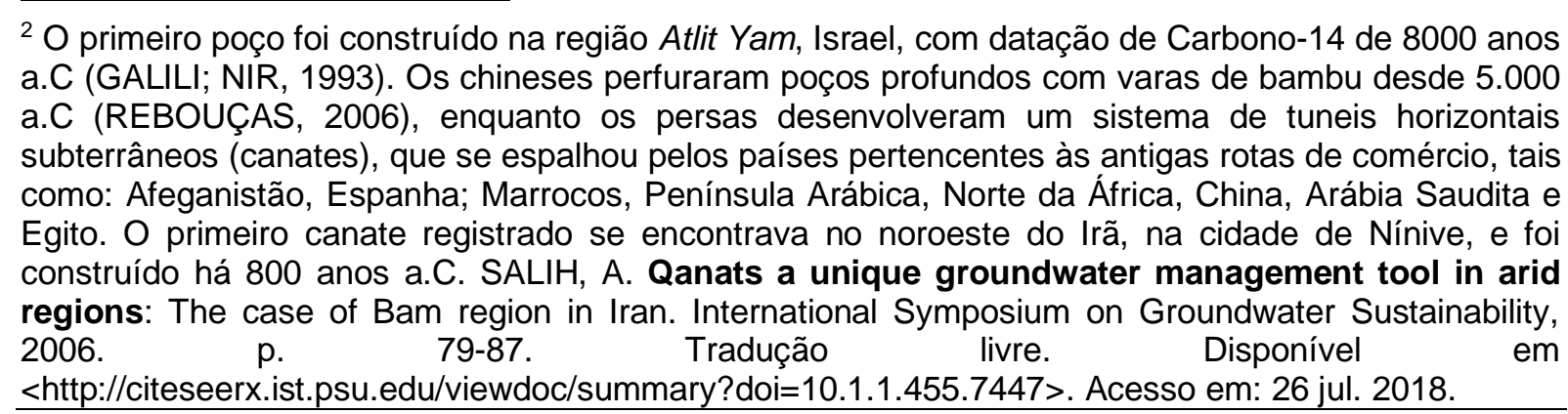


as técnicas de uso e exploração das águas subterrâneas não causavam tantos impactos e ameaças ao desenvolvimento e sobrevivência da sociedade humana.

Segundo o IBGE (2008), no Brasil existem 5.564 municípios com rede geral de distribuição de água, entre os quais $76 \%$ utilizam águas subterrâneas. Embora a maioria dos municípios utilize mais de uma fonte de captação de água bruta; 3.545 utilizam a água proveniente de poços profundos; 3.141 municípios utilizam águas superficiais; e 688 municípios utilizam água de poços rasos.

Há ainda que se ressaltar a existência e importância de aquíferos transfronteiriços, ou seja, aqueles que perpassam por mais de um Estado, não respeitando limites fronteiriços entre estados-membros e Estados.

São sistemas compartilhados por mais de um Estado, e sua gestão, também compartilhada, decorre de acordos e tratados bilaterais e multilaterais. Nesta linha, relata Villar (2007, p. 65-66) que:

\begin{abstract}
A constatação da existência de importantes Aquíferos tranfronteiriços, da carência de informação sobre esses e a falta de políticas globais ou instrumentos legais apropriados para a gestão desses recursos, fez com que a Associação Internacional de Hidroeologistas (IAH) sugerisse no Congresso de Nottingham em 1997 uma proposta para a criação de uma comissão de investigação para tratar dos problemas e questões relativos aos Aquíferos transfronteiriços.
\end{abstract}

O tema das águas subterrâneas transfronteiriças demora a ganhar destaque na agenda internacional; as normas, no plano internacional, preocupam-se, primordialmente, em regular a navegação e demais usos das águas (rios) transfronteiriços (recursos hídricos superficiais). A esta ausência de regulamentação, quiçá pelo interesse dos governantes no assunto, deve-se, inicialmente, à falta de informação e dados técnicos acerca dos aquíferos transfronteiriços, bem como, à inutilidade de águas subterrâneas para navegação, pesca ou produção de energia elétrica, assuntos que efetivamente eram objeto de conflito entre os Estados.

O assunto fortalece-se em meados de 1999, quando a Comissão de Direito Internacional da Organização das Nações Unidas compreende que as regras 
internacionais relativas à navegação de águas transfronteiriças não se adequavam às águas subterrâneas, passando a concentrar esforços na temática.

Nesta linha, a Resolução №. 63/124³ da Assembleia Geral da Organização das Nações Unidas, de 15 de janeiro de 2009, sobre o Direito dos Aquíferos Transfronteiriços, enaltece a importância e necessidade de regulamentação dos aquíferos transfronteiriços. Embora sem efeitos vinculantes, reconhece a importância das águas subterrâneas para a humanidade e a necessidade de regular seu aproveitamento e uso de forma sustentável.

Quanto aos recursos hídricos transfronteiriços, o relatório da Unesco de 2012, o 4․ World Water Development Report registra haver atualmente 263 bacias hidrográficas internacionais que ultrapassam fronteiras políticas de um Estados, e 148 Estados soberanos nelas inseridos, ainda que parcialmente. O mesmo documento identificou pelo menos 273 aquíferos transfronteiriços ao redor do mundo. Os três principais aquíferos do planeta são: o Sistema Aquífero de Arenito Núbio, no norte da África, com 2 milhões de quilômetros quadrados; a Grande Bacia Artesiana, no meio-oeste americano, com 1,7 milhão de quilômetros quadrados; e o Sistema Aquífero Guarani, com 1,2 milhão de quilômetros quadrados (Relatório Mundial das Nações Unidas sobre Desenvolvimento dos Recursos Hídricos, 2016).

$\mathrm{O}$ assunto ganha ainda mais destaque quando a solução para o tema da poluição e escassez da água envolvem grupos de diferentes Estados soberanos; ou seja, a problemática dos aquíferos transfronteiriços vincula-se diretamente à questão de soberania, tema de maior bloqueio para a cooperação internacional na proteção e gestão de recursos hídricos transfronteiriços. É nela que esbarra grande parte das iniciativas bilaterais ou regionais.

Como explica Brzezinski (2011), a soberania estatal assume um papel fundamental em determinar o direito e as relações internacionais das águas doces, seja entendida como a "qualificação do poder exercido pelos Estados sobre seus

\footnotetext{
${ }^{3}$ A Resolução é composta por um preâmbulo e 19 artigos, divididos em quatro partes: introdução; princípios gerais; proteção, preservação e gestão; e disposições diversas. Disponível em UNITED NATIONS. General Assembly. Resolution adopted by the General Assembly. 63/124 The law of transboundary aquifers. Disponível em: <http://undocs.org/en/A/RES/63/124>. Acesso em: 26 jul. 2018.
} 
recursos naturais" ou "como impedimento para se alcançar um determinado acordo, ainda que de forma implícita".

\section{SISTEMA AQUíFERO GUARANI - SAG: REGIME JURÍDICO DE COOPERAÇÃO NA GESTÃo E PRESERVAÇÃO}

Como seu nome já anuncia, o Sistema Aquífero Guarani é um conjunto de unidades aquíferas continuas e ligadas hidraulicamente e, segundo Guimarães (2007, p. 27), "os sistemas aquíferos devido ao isolamento parcial dos impactos em superfície, em geral possuem águas de excelente qualidade".

O Aquífero Guarani - outrora denominado Aquífero Botucatu -, um dos maiores e mais importantes do Planeta, localizado na região centro-leste da América do Sul, estende-se sobre os territórios do Brasil, Paraguai, Uruguai e Argentina 4 .

Diante de todo seu potencial, bem como pelo risco de degradação e poluição de suas reservas, os Estados esforçaram-se na criação do Projeto de Proteção Ambiental e Desenvolvimento Sustentável do Sistema Aquífero Guarani, em parceria com a OEA, o Banco Mundial e o Fundo Mundial para o Meio Ambiente (GEF), evidenciando em seu preâmbulo o espírito de cooperação e integração dos Estados, bem como o propósito de alargá-lo para maior proteção e aproveitamento das águas do referido Aquífero.

O acordo foi firmado pelos quatro Estados em agosto do ano de 2010, mas, embora represente um avançado precedente regional, ainda depende de ratificação e regulamentação por todos os Estados para tornar-se efetivo. Em âmbito nacional, registre-se que o acordo foi aprovado pelo Senado brasileiro em maio de 2017, o que então permite sua ratificação formal e consequente entrada em vigor (Acordo sobre o Aquífero Guarani).

O artigo primeiro do Acordo reafirma a soberania dos quatro Estados sobre as águas do Aquífero, quando estabelece que:

\footnotetext{
${ }^{4}$ No território nacional compreende regiões nos Estados de Goiás, Mato Grosso do Sul, Minas Gerais, São Paulo, Paraná e Rio Grande do Sul.
} 
O Sistema Aquífero Guarani é um recurso hídrico transfronteiriço, que integra o domínio territorial soberano da República Argentina, República Federativa do Brasil, República do Paraguai e República Oriental do Uruguai, que são os únicos titulares desse recurso e doravante serão denominados 'Partes'.

Ainda sobre $o$ assunto soberania, o acordo, reforça nos artigos $2^{\circ}$. e $3^{\circ}$. o entendimento de que os recursos do Aquífero Guarani pertencem e são de responsabilidade dos Estados pelos quais ele se estende ${ }^{5}$.

Estudos mostram que a água que se bebe do Aquífero tem entre mil e dois mil anos, o que comprova que a recarga é lenta, informa o engenheiro civil Carlos Alencastre, presidente da Associação de Engenharia e Arquitetura e Agronomia de Ribeirão Preto (2016, p. 05). Some-se a isto, a ilusão de fartura hídrica e a superexploração dos aquíferos que, em curto prazo, trazem benefícios econômicos, todavia, em médio e longo tempo, provocam consequências desastrosas.

O Acordo é um documento que foi fundado com base no interesse dos Estados em reafirmar sua soberania frente a outros Estados, ou por questões voltadas para as pressões oriundas das organizações internacionais que investiram durante o período do PSAG, como também pela preocupação com o meio ambiente.

Conforme já explanado, o acordo foi importante, pois possibilitou a criação de um novo modelo de cooperação para a proteção dos recursos compartilhados, um precedente regional em 2010, porém, ainda espera o comprometimento dos Estados para a sua ratificação e regulamentação. A Argentina e o Uruguai ratificaram em 2012, todavia o Brasil e o Paraguai tiveram a aprovação recente do Acordo em seus Congressos Nacionais, respectivamente 2017 e 2018. Com isso, aguardam a aprovação pelo Executivo em seus Estados para que possa entrar em vigor.

Assim, a edição do Acordo representa um marco regulatório no tema e consolida a necessidade de uma imediata reflexão sobre o regime jurídico apto a

\footnotetext{
${ }^{5}$ Artigo 1 - O Sistema Aquífero Guarani é um recurso hídrico transfronteiriço que integra o domínio territorial soberano da República Argentina, República Federativa do Brasil, República do Paraguai e República Oriental do Uruguai, que são os únicos titulares desse recurso e doravante serão denominados "Partes" (grifo nosso). Artigo 2 - Cada Parte exerce o domínio territorial soberano sobre suas respectivas porções do Sistema Aquífero Guarani, de acordo com suas disposições constitucionais e legais e de conformidade com as normas de direito internacional aplicáveis.
} 
regular, seja nacional ou internacionalmente, a utilização das águas subterrâneas do Aquífero de forma equitativa, cooperada e consciente.

\section{CONSIDERAÇÕES FINAIS}

A utópica e romântica concepção que marcava os discursos do início do Século XXI, de que o Aquífero Guarani teria volume e qualidade de água suficientes ao abastecimento humano, afastando a problemática da crise hídrica nos Estados do Cone Sul, não mais se sustenta.

É bastante provável que as próximas décadas serão marcadas por uma luta ainda mais intensa pela água, da qual pode decorrer uma trágica consequência: os pequenos Agricultores e os integrantes do segmento mais pobre da população terão seu direito de acesso à água potável destruído pelos mais fortes e poderosos. E não tardará que esse mesmo direito seja cada vez mais raro também para toda a população.

A mobilização da Ciência e do Direito torna-se sempre mais fundamental para a adequada gestão dos aquíferos transfronteiriços, sob o fato de que o grande desafio é articular diferentes interesses nacionais dos Estados soberanos que os compartilham.

A assinatura do Acordo sobre o Aquífero Guarani, em 2010, pelos Estados do Mercosul, estimula a cooperação entre os Estados e, se efetivamente implementado, estará indo ao encontro dos Objetivos de Desenvolvimento Sustentável (ODS), publicado pela Organização das Nações Unidas no ano de 2015, que busca "garantir disponibilidade e manejo sustentável da água e saneamento para todos (ODS 6), e pretende fortalecer mecanismos de implementação e revitalizar a parceria global para o Desenvolvimento Sustentável (ODS 17)". Destacam Souza e Guilard (2017), o desenvolvimento integra a vida cotidiana, porém, pede sempre que seja "consciente e sustentável". 
Diferentemente do que se poderia imaginar, o Acordo não representa apenas uma restrição indevida à soberania nacional dos Estados que o firmaram, mas a promoção do intercâmbio de melhores práticas de gestão das águas subterrâneas. Assim, ocorrerá através da institucionalização do próprio Acordo e de reuniões regulares, nas quais os Estados apresentam suas comunicações de forma voluntária.

E, também, o Acordo desperta a atração de investimentos e financiamentos aos Estados, permitindo o retorno de projetos que trarão mais conhecimento técnico e científico sobre o Aquífero, através de programas ambientais e de cooperação internacional.

No entanto, a demora e os entraves para transformar o acordo em iniciativas concretas de cooperação na gestão e preservação do Aquífero não tardarão a agravar os danos irreparáveis à natureza e, consequentemente, à humanidade.

É necessário admitir a possibilidade de haver tensões transfronteiriças nas regiões abarcadas pelo Sistema. Ressalte-se que a ausência de políticas públicas eficientes e de cooperação internacional certamente agravarão o perigo, já tão iminente.

Enfim, é imprescindível a conscientização de todos os Estados no sentido de que a água potável é essencial à vida da humanidade, como também ela é um elemento finito da natureza e, portanto, o seu desperdício e a sua má gestão afetarão diretamente o bem-estar de toda a sociedade.

\section{REFERÊNCIAS}

ALENCASTRE, Carlos. Aquífero Guarani: Desafios Técnicos e Legais. Painel. Associação de Engenharia, Arquitetura e Agronomia de Ribeirão Preto. Ano IX, $\mathrm{n}^{\circ} 258$, setembro/2016

AGÊNCIA NACIONAL DE AGUAS - ANA - Panorama das águas no mundo. Disponível em: <http://www3.ana.gov.br/portal/ANA/panorama-das-aguas/agua-nomundo $\geq$. 
BRASIL. Decreto-Legislativo 52, de 2017. Aprova o texto do Acordo sobre o Aquífero Guarani, firmado em San Juan, República Argentina, em 2 de agosto de 2010. Disponível em: $<$ http://www2.camara.leg.br/legin/fed/decleg/2017/decretolegislativo-52-3-maio-2017784714-acordo-152560-pl.html>.

BRZEZINSKI, M. L. N. L. Direito Internacional em matéria de água doce: conteúdo, formas e efetividade. 2011. $382 \mathrm{f}$. Tese (Doutorado em Direito) Faculdade de Direito, Universidade do Estado do Rio de Janeiro, Rio de Janeiro, 2011.

FERRAJOLI, Luigi. Por uma Teoria dos Direitos e dos Bens Fundamentais. Tradução de Alexandre Salim, Alfredo Copetti Neto, Daniela Cademartori, Hermes Zaneti Júnior, Sérgio Cademartori. Porto Alegre: Livraria do Advogado, 2011. (sem título original no exemplar utilizado).

GRANZIERA, Maria Luiza Machado. Direito de águas: disciplina jurídica das águas doces. 3.ed.São Paulo: Atlas, 2006.

GUIMARAES, Luiz Ricardo. Desafio jurídicos na proteção do Sistema Aquífero Guarani. São Paulo: LTr, 2007.

INSTITUTO BRASILEIRO DE GEOGRAFIA E ESTATISTICA - Pesquisa Nacional de Saneamento Básico 2008. Tabela 28 - Municípios, total e com serviço de abastecimento de água por rede geral de distribuição, por tipo de captação, segundo as Grandes Regiões e as Unidades da Federação - 2008. Rio de Janeiro: IBGE, $2010 . \quad$ Disponível em: <https://ww2.ibge.gov.br/home/presidencia/noticias/imprensa/ppts/0000000105.pdf>.

Objetivo do Desenvolvimento Sustentável. Disponível em: https://nacoesunidas.org/pos2015/. Acesso em: 3 mai. 2019.

Objetivo do Desenvolvimento Sustentável. ODS. Disponível em: $<$ https://nacoesunidas.org/conheca-os-novos-17-objetivos-de-desenvolvimentosustentavel-da-onu>. Acesso 3 mai. 2019.

ORGANIZAÇÃO DAS NAÇÕES UNIDAS. O direito humano à água e saneamento: marcos. Portal da Organização das Nações Unidas, [2011]. Disponível em: $<$ http://www.un.org/waterforlifedecade/pdf/human_right_to_water_and_sanitation_mil estones_por.pdf $>$.

ORGANIZAÇÃO DAS NAÇÕES UNIDAS-ONU. Declaração Universal dos Direitos da Água. http://www.direitoshumanos.usp.br/index.php/Meio-Ambiente/declaracaouniversal-dos-direitos-da-agua.html>. Acesso em: 26 dez. 2018. 
ORGANIZAÇÃO DAS NAÇÕES UNIDAS. Agenda 21. Portal Ecolnews, 1992. Disponível em: <http://www.ecolnews.com.br/agenda21/>.

PASOLD, Cesar Luiz. Metodologia da Pesquisa Jurídica. Teoria e Prática. 14.ed.rev.amp.atual. Florianópolis: Emais, 2018.

. Ainda sobre a Água Potável. Imbituba: O Popular, 07/04/2006. p.2.

PROGRAMA DAS NAÇOES UNIDAS PARA O DESENVOVIMETNO (PNDU):2006. Relatório do Desenvolvimento Humano. A água pra lá da escassez: poder, pobreza e a crise mundial da água. Publicado para o Disponível em: <http://www.br.undp.org/content/brazil/pt/home/library/idh/relatorios-dedesenvolvimento-humano/relatorio-do-desenvolvimento-humano-20006.html>.

SALIH, A. Qanats a unique groundwater management tool in arid regions: The case of Bam region in Iran. International Symposium on Groundwater Sustainability, 2006.

Disponível

em: $<$ http://citeseerx.ist.psu.edu/viewdoc/summary?doi=10.1.1.455.7447>.

SARLET, Ingo Wolfang et FENSTERSEIFER, Tiago. Direito Constitucional Ambiental. Constituição. Direitos Fundamentais e Proteção do Ambiente. 5.ed.rev.atual.amp.São Paulo: Revista dos Tribunais, 2017.

SHIKLOMANOV, I.A; RODDA, J.C. (Eds). World water resosurces at the beginning of the 21st century. Cambridge, UK: UNESCO Internacional Hydrology Series, 2003.

SOUZA, Maria Cláudia da Silva Antunes de. GHILARDI, Hilariane Teixeira. Recursos hídricos, agropecuária e sustentabilidade: desafios para uma visão ecológica do planeta. Revista Unicuritiba. 2017. Vol. 2 n. 47. p. 78-98.

SOUZA, Maria Cláudia da Silva Antunes de. POMPEU, Gina Vidal Marcilio. FREITAS, Ana Carla Pinheiro. Gestão das águas: Dignidade Humana e Sustentabilidade por meio do fortalecimento das cadeias de Valor. $2^{2}$ Edição. Rio de Janeiro: Editora Lumen juris. 2019.

UNITED NATIONS. General Assembly. Resolution adopted by the General Assembly. 63/124 The law of transboundary aquifers. Disponível em: $<$ http://undocs.org/en/A/RES/63/124>.

VILLAR, Pilar Carolina. A gestão internacional dos recursos hídricos subterrâneos transfontreiriços e o Aquífero Guarani. REGA - Vol.4.n1, p.63-74, jan/jun.2007. Disponível em $<$ https://www.abrh.org.br/SGCv3/index.php?PUB=2\&ID=69\&SUMARIO=845>. Acesso em: 25 jul. 2018. 
VILLAR, Pilar Carolina. A busca pela governança dos aquíferos transfronteiriços e o caso do aquífero guarani. - São Paulo, 2012. 261 f . Tese de Doutorado. 